\title{
Formação de professores de inglês no Pibid: um mapeamento de estudos
}

\author{
English teacher education at Pibid: a mapping study
}

La formación del profesorado de inglés en Pibid: un mapeo de estúdios

\author{
Bruna Sampaio Silgueiro Mardegan* \\ Anna Augusta Cazeloto Ioris* \\ Luciana Cabrini Simões Calvo*
}

Dhttps://orcid.org/0000-0002-3952-9214

https://orcid.org/0000-0001-7235-595X

https://orcid.org/0000-0001-8145-0588

\begin{abstract}
RESUMO: Tendo como foco o Programa Institucional de Bolsa de Iniciação à Docência (PIBID), este artigo tem como objetivo geral realizar um levantamento de estudos recentes, desenvolvidos entre 2014 a 2018, que tratam da formação de professores de língua inglesa no referido contexto. De modo específico, o trabalho visa compreender quais são os avanços e as lacunas do conjunto de estudos levantado. As pesquisas foram realizadas no Google Acadêmico e no portal de dissertações e teses da Capes. Ademais, foi analisada a coletânea de El Kadri et al. (2018). Os 37 trabalhos selecionados foram classificados conforme seus focos investigativos, metodologia e participantes da pesquisa; além dos resultados alcançados. Evidenciou-se um foco de investigação mais predominante na formação docente inicial, com os alunos de graduação participantes do programa. As pesquisas qualitativas se sobressaíram, com o emprego de diferentes instrumentos para coleta/geração de dados. Alguns dos resultados mostraram a ressignificação de identidades e relações por parte dos pibidianos; outros apresentaram o Pibid como um lugar de experienciar práticas alternativas. Como pontos ainda a serem explorados, destacamos a formação docente continuada de supervisores e coordenadores no âmbito do programa; um acompanhamento dos egressos e a articulação do estágio com o Pibid.
\end{abstract}

PALAVRAS-CHAVE: Pibid-Inglês. Mapeamento de estudos. Formação de professores.

ABSTRACT: This paper is focused in the Institutional Teaching Initiation Scholarship Program (Pibid). This way the general objective is conducting a survey of recent studies, developed between 2014 to 2018, which deal with English language teachers education in this context. Specifically, this work aims to understand the advances and gaps in the selected corpus of studies. The research was carried out on Google Scholar and on Capes' dissertations and theses portal. In addition, the collection of El Kadri et al. (2018) was analyzed. The 37

\footnotetext{
* Mestranda do Programa de Pós-graduação em Letras da Universidade Estadual de Maringá (PLE/UEM). E-mail: brunasilgueiro@gmail.com

* Graduanda do curso de Letras da Universidade Estadual de Maringá (DLE/UEM). E-mail: annacioris@gmail.com

* Professora do Departamento de Letras Modernas e do Programa de Pós-graduação em Letras da Universidade Estadual de Maringá. E-mail: $\underline{\text { Icsimoes@uem.br }}$
} 
selected works were classified according to their investigative focus, methodology and research participants; beyond the results achieved. A more prevalent research focus was evidenced in initial teacher education, with the undergraduate students of the program. Qualitative research stood out, with the use of different instruments for data collection / generation. Some of the results showed the resignification of identities and relationships on the part of the pibidians; others presented Pibid as a place to experience alternative practices. With points that yet should be explored, we highlighted the continued teacher education of supervisors and coordinators within the scope of the program; monitoring its graduates and articulating the internship with Pibid.

KEYWORDS: English Institutional Teaching Initiation Scholarship Program. Mapping study. Teacher education.

RESUMEN: Centrándonos en el Programa de Becas de Iniciación a la Enseñanza Institucional (PIBID), el objetivo de este artículo es realizar una encuesta de estudios desarrollados entre 2014 y 2018, que abordan la formación de profesores de inglés en el contexto referido. En concreto, el trabajo tiene como objetivo comprender cuáles son los avances y brechas en el corpus de estudios seleccionados. Se utilizó el portal de disertaciones y tesis de Capes y Google Scholar. Además, se analizó la colección de El Kadriet al. (2018). Los 37 trabajos seleccionados fueron clasificados según su enfoque de investigación, metodología y participantes de la investigación; más allá de los resultados obtenidos. Un enfoque de investigación más prevalente se evidenció en la formación inicial del profesorado, con la participación de estudiantes de pregrado. Se destacó la investigación cualitativa, con el uso de diferentes instrumentos para la recolección /generación de datos. Algunos resultados mostraron la resignificación de identidades y relaciones por parte de los pibidianos; otros presentaron a PIBID como un lugar para experimentar prácticas alternativas. Los puntos a explorar son la formación continua del profesorado de los supervisores y coordinadores; seguimiento de los egresados y articulación de la pasantía con PIBID.

PALABRAS CLAVE: Pibid-Inglés. Estudio de mapeo. Formación de profesores.

\section{Introdução}

O foco deste artigo é o Programa Institucional de Bolsa de Iniciação à Docência (PIBID), que oferta bolsas a licenciandos participantes de projetos de iniciação à docência desenvolvidos por instituições de educação superior (IES) juntamente com as redes de ensino (CAPES, 2018). Com esse foco em tela, o objetivo do presente artigo é realizar um levantamento de estudos recentes, desenvolvidos entre os anos de 2014 a 2018, que tratam da formação de professores de língua inglesa no referido contexto, com vistas a observar avanços e lacunas do conjunto de pesquisas com esse foco.

O programa em questão busca aproximar os alunos que estão na primeira metade do curso de licenciatura com o cotidiano das escolas públicas de educação básica, a fim de estimular a observação e a reflexão sobre a prática profissional nesses contextos. Esses alunos bolsistas, aqui chamados "pibidianos", são acompanhados por um professor 
da escola pública (supervisor) e por um docente (coordenador) de uma da instituição de ensino superior, doravante IES.

Contribuir para a valorização do magistério e incentivar a formação de docentes para atuarem na educação básica é um dos maiores objetivos do Pibid, que também tem o propósito de elevar a qualidade da formação inicial, integrando a educação básica e a educação superior.

Ademais, o Pibid incentiva as escolas públicas de educação básica a mobilizar os professores a serem coformadores dos licenciandos, fazendo-os protagonistas nos processos de formação inicial (CAPES, 2018). Além disso, para melhorar as ações acadêmicas nos cursos de licenciatura, o projeto procura contribuir para a articulação entre teoria e prática, indispensáveis na formação.

Ao trazer concepções da perspectiva sócio-histórico-cultural de formação de professores, Gimenez (2013) destaca que programas como o Pibid procuram integrar a formação inicial e continuada em comunidades de aprendizagem. Para a autora, oportunidades que possibilitam a interação entre os diferentes membros da comunidade (novatos e mais experientes) contribuem para a geração de novas identidades e aprendizagens. Em suas palavras:

[...] a formação inicial pode ser entendida como o engajamento em práticas profissionais por meio de trajetórias no interior da comunidade, integrando membros com diferentes graus de experiência e conhecimento. Por outro lado, formação continuada constitui-se de oportunidades para negociação dos sentidos atribuídos ao ensino e suas ligações com ações pedagógicas que constituem parte do repertório de práticas sob negociação (GIMENEZ, 2013, p. 50).

Com destaque para "a construção do fazer pedagógico" de professores nos variados níveis de ensino, Jordão (2018) salienta que, no contexto do Pibid, os supervisores abrem suas salas, seus planos de aula e seus (pre)conceitos com licenciandos e formadores; esses, por sua vez, são responsáveis pela formação dos licenciandos juntamente com os supervisores - "o formador também é instado a, no processo colaborativo, negociar (pre)conceitos, experimentar outras perspectivas de ensino-aprendizagem, questionar suas crenças diante da realidade de trabalho do professor supervisor" (JORDÃO, 2018, p. 9). Os licenciandos, de acordo com a autora, 
vivenciam teoria-prática, experienciam o que estudam nas licenciaturas, exercem diretamente a profissão, com o suporte de seus formadores.

Tendo em vista os objetivos do programa em relação à formação de professores, a motivação para este artigo surgiu do desejo de mapear as recentes pesquisas que articulam a formação docente e o contexto do Pibid, para melhor compreender, por meio dos estudos de base secundária, os avanços, bem como identificar lacunas para possíveis investigações e ações formativas.

A busca atentou especificamente para trabalhos que tratam da formação de professores de língua inglesa, sendo assim, as palavras-chave utilizadas foram: Formação de professores, Língua Inglesa e Pibid. As pesquisas foram feitas nas plataformas do Google Acadêmico e no portal de dissertações e teses da Capes. Para o filtro da pesquisa, foram utilizados, primeiramente, o período de 2014 a 2018, e os textos selecionados foram os das páginas 1 a 5 de cada plataforma, pois eram os que tinham foco mais explícito com o mapeamento realizado.

Juntamente com essa seleção online foi utilizado um livro que articula esses dois focos: A formação de professores de inglês no contexto do PIBID: Relatos de pesquisas acadêmicas, de El Kadri, Calvo, Chimentão e Mulik, publicado em 2018. Os resultados totalizaram 37 estudos que abordavam o Pibid-Inglês e a formação de professores. É importante ressaltar que outras pesquisas foram encontradas, porém, somente aquelas que incluíam todos os tópicos da busca (Formação de professores, Língua Inglesa e Pibid) foram selecionadas.

O mapeamento aqui apresentado pode, também, ser considerado uma metassíntese qualitativa (ALENCAR; ALMOULOUD, 2017, p. 206), pois "realiza uma revisão sistemática de investigações qualitativas", permitindo uma compreensão aprofundada do objeto estudado.

A seguir, são apresentados os resultados considerando as pesquisas realizadas nas fontes indicadas, tendo como base os resumos dos materiais selecionados e, no caso dos capítulos do livro, as introduções.

\section{Análise dos textos selecionados}

Com o propósito de apresentar os resultados obtidos, os trabalhos foram classificados de acordo com: focos investigativos, metodologia empregada, participantes da pesquisa e resultados alcançados. 


\section{Focos investigativos}

Em relação ao foco das investigações desenvolvidas, esse foi variado, pois alguns trabalhos buscaram descrever o projeto em si, como o artigo de Lopes et al. (2014), cujo objetivo foi apresentar o subprojeto do Pibid-Inglês da UEG.

Outros estudos abordaram o Pibid enquanto contexto, atentando para variados aspectos teórico-metodológicos, como: as práticas de oralidade, a exemplo da pesquisa de Trevisol, Santos e Alves (2014); a gamificação, como no artigo de El Kadri (2015); a ferramenta vodcast, presente no artigo de Reis e Sabota (2015); e a questão da cultura, no artigo de Rozenfeld e Salomão (2014). A respeito deste foco é importante frisar que, mesmo os trabalhos que tem como objetivo avaliar o funcionamento de alguma prática ou atividade específica no contexto do Pibid, esses também abordam, ainda que sutilmente, o impacto de tais práticas e do próprio contexto na formação docente, a exemplo do trabalho de Trevisol, Santos e Alves (2014), segundo o qual foi possível notar não apenas o desenvolvimento comunicativo dos participantes, mas também 0 desenvolvimento dos pibidianos em sua formação.

Estudos que abordam a formação inicial de professores foram os mais observados, com trabalhos que tratam dos dizeres de licenciandos e como eles revelam o seu pensamento (e.g. REICHMANN; MORAIS, 2018), da produção de significados no contexto da formação inicial (BALADELI; VON BORSTEL; FERREIRA, 2016; ZANELLA; CARNEIRO, 2015) das crenças do professor em formação em relação ao ambiente escolar (MAIA, 2014). Há ainda os que abordaram a relação entre Pibid e estágio (MOTTA; SILVA, 2014), e o desenvolvimento das competências e da autonomia dos licenciandos (KAUST; PAIZAN, 2017).

Dentre os trabalhos que tratam da formação inicial, o tópico identidade e representações dos pibidianos tem destaque, com estudos como os de Petreche e Silva (2018), Baladeli $(2015,2018)$ e Baladeli, Von Borstel e Ferreira (2016), que tiveram como aporte teórico os Novos Estudos do Letramento (BALADELI, 2015; STREET, 2003) e os estudos sobre identidade (HALL, 2009; JENKLINK, 2014; NORTON; EARLY, 2011).

Há também alguns trabalhos que tratam da formação continuada de professores, atentando especialmente para o papel co-formador do supervisor no Pibid, a exemplo da tese de Justina (2016), que se baseou em estudiosos como Mateus (2013), Cox e AssisPeterson (2007) e Jonhson (2009). 
Outro foco levantado se ateve tanto à formação inicial quanto à continuada, abordando o desenvolvimento profissional e a formação de pibidianos, coordenadores e supervisores. Dentro dessa categoria, a maioria dos estudos aborda a formação inicial e continuada sob a ótica da formação colaborativa e dos espaços colaborativos. A exemplo disso temos o artigo de Fiori-Souza (2014), que buscou, com base na Teoria da Atividade de Engestrom $(2008,2011)$ e na Análise do Discurso Crítica de Fairclough (2003), investigar as contradições evidenciadas nos espaços de formação do Pibid ${ }^{1}$.

Quadro 1 - Organização dos trabalhos de acordo com seus focos investigativos

\begin{tabular}{|l|l|}
\hline \multicolumn{1}{|c|}{ Focos investigativos } & \multicolumn{1}{c|}{ Trabalhos } \\
\hline $\begin{array}{l}\text { O Pibid em si (apresentação da } \\
\text { configuração do projeto Inglês) }\end{array}$ & $\begin{array}{l}\text { Lopes et al. (2014); Reis et al. (2014b); Romero (2017); } \\
\text { Rocha (2014); Denardi (2014). }\end{array}$ \\
\hline $\begin{array}{l}\text { O Pibid enquanto contexto, } \\
\text { atentando para variados } \\
\text { aspectos teórico-metodológicos }\end{array}$ & $\begin{array}{l}\text { Trevisol, Santos e Alves (2014); El Kadri (2015); Reis e } \\
\text { Sabota (2015); Rozenfeld e Salomão (2014) }\end{array}$ \\
\hline Formação docente inicial & $\begin{array}{l}\text { Reichmann e Morais (2018); Zanella e Carneiro (2015); } \\
\text { Maia (2014); Motta e Silva (2014); Kaust e Paizan (2017); } \\
\text { Petreche e Silva (2018), Baladeli (2015; 2018); Rocha et } \\
\text { al. (2014); El Kadri (2018); Lanferdini e Cristovão (2018); } \\
\text { Baladeli, Von Borstel e Ferreira (2016); Neres (2014). }\end{array}$ \\
\hline $\begin{array}{l}\text { Formação continuada do } \\
\text { supervisor }\end{array}$ & $\begin{array}{l}\text { Justina (2016); Trevisol e Lima (2014); Hibarino (2015); } \\
\text { Mulik (2014); Reis et al. (2014b). }\end{array}$ \\
\hline $\begin{array}{l}\text { Formação docente inicial e } \\
\text { continuada }\end{array}$ & $\begin{array}{l}\text { Fiori-Souza (2014); Mateus e Fiori-Souza (2017); Barbosa- } \\
\text { Silva (2015); Mulik (2018); Gaffuri (2018); Chimentão } \\
\text { (2014; 2018); Silvestre (2014); Rorrato (2014); Araujo } \\
\text { (2015). }\end{array}$ \\
\hline
\end{tabular}

Fonte: Elaborado pelas autoras.

\section{Metodologia de pesquisa e seus participantes}

A respeito da metodologia empregada, em termos de natureza, seis pesquisas, explicitamente, denominaram-se qualitativas; epistemologicamente, três autoconceituaram-se como interpretativistas: os trabalhos de Araujo (2015), Justina (2016) e Mulik (2014). No que tange à tipologia da pesquisa, uma afirmou ter se utilizado de estudo de caso (EL KADRI, 2018), uma de pesquisa-ação (TREVISOL; LIMA, 2014) e quatro de bases etnográficas: Mulik (2014), Neres (2014), Justina (2016) e Silva (2015).

\footnotetext{
${ }^{1}$ Os estudos que integraram o referencial teórico embasaram algumas das pesquisas do mapeamento não são referências diretas no presente artigo. Por isso, Street (2003), Cox e Assis-Peterson (2007). Fairdough (2003), dentre outros, não parecem nas nossas referências.
} 
Dos instrumentos utilizados, foram mencionados: questionários, entrevistas, transcrições de reuniões, relatos de experiência e diários.

É válido pontuar que, embora seis pesquisas se denominem qualitativas em seus resumos, algumas trazem essa natureza de investigação no corpo do texto, o que não foi contabilizado aqui devido ao recorte do mapeamento, que examinou mais atentamente os resumos e, no caso dos capítulos de livro, as introduções.

Em relação aos participantes dessas pesquisas, trabalhos cujos participantes são todos os envolvidos no programa (pibidianos, supervisoras e coordenadoras) totalizam 15 estudos, dentre os quais, vale ressaltar, cinco são pesquisas que buscam descrever o programa em si e também avaliar seu impacto em todos os que dele participam.

A maioria das pesquisas voltou-se exclusivamente ao aluno de graduação participante do Pibid-inglês, totalizando 17 estudos, sendo que a maior parte deles trata da formação inicial. As pesquisas que levam em consideração apenas a perspectiva das supervisoras do programa aparecem em menor número e totalizam cinco estudos (HIBARINO, 2015; JUSTINA, 2016; MULIK, 2014; REIS et al., 2014a; TREVISOL; LIMA, 2014), enquanto não encontramos pesquisas que abordem apenas os/as coordenadores/as do programa.

Quadro 2 - Organização dos trabalhos de acordo com sua metodologia

\begin{tabular}{|l|l|}
\hline $\begin{array}{l}\text { Metodologia (natureza, epistemologia } \\
\text { e tipologia) }\end{array}$ & \multicolumn{1}{|c|}{ Trabalhos } \\
\hline $\begin{array}{l}\text { Pesquisas que explicitamente se } \\
\text { denominaram de natureza qualitativa }\end{array}$ & $\begin{array}{l}\text { Reichmann e Morais (2018); Maia (2014); Araujo } \\
\text { (2015); Neres (2014); Justina (2016); Barbosa-Silva } \\
(2015) .\end{array}$ \\
\hline $\begin{array}{l}\text { Pesquisas que explicitamente se } \\
\text { denominaram de epistemologia } \\
\text { Interpretativista }\end{array}$ & Araujo (2015); Justina (2016); Mulik (2014) \\
\hline Estudo de caso & El Kadri (2018) \\
\hline Pesquisa-ação & Trevisol e Lima (2014) \\
\hline De bases etnográficas & $\begin{array}{l}\text { Mulik (2014); Neres (2014); Justina (2016); Barbosa- } \\
\text { Silva (2015) }\end{array}$ \\
\hline
\end{tabular}

Fonte: Elaborado pelas autoras. 
Mardegan, B. S. S.; Ioris, A. A. C.; Calvo, L. C. S.

Quadro 3 - Participantes das pesquisas analisadas

\begin{tabular}{|l|l|}
\hline Participantes da pesquisa & \multicolumn{1}{|c|}{ trabalhos } \\
\hline $\begin{array}{l}\text { Todos os envolvidos no } \\
\text { programa }\end{array}$ & $\begin{array}{l}\text { Mateus e Fiori-Souza (2017); Motta e Silva (2014); Silvestre } \\
\text { (2014); Denardi (2014); Lopes et al. (2014); Romero (2017); } \\
\text { Rocha (2014); Chimentão (2014); Reis et al. (2014a); Fiori- } \\
\text { Souza (2014); Araujo (2015); Barbosa-Silva (2015); Gaffuri } \\
\text { (2018); Mulik (2018); Chimentão (2018). }\end{array}$ \\
\hline Pibidianos & $\begin{array}{l}\text { Reichmann e Morais (2018); Baladeli, Von Borstel e Ferreira } \\
\text { (2016); Trevisol, Santos e Alves (2014); El Kadri (2015); } \\
\text { Rozenfeld e Salomão (2014); Rorrato (2014); Zanella e } \\
\text { Carneiro (2015); Reis e Sabota (2015); Kaust e Paizan (2017); } \\
\text { Petreche e Silva (2018); Rocha et al. (2014); Maia (2014); } \\
\text { Baladeli (2015); Neres (2014); Lanferdini e Cristóvão (2018); El } \\
\text { Kadri (2018); Baladeli (2018). }\end{array}$ \\
\hline Supervisores & $\begin{array}{l}\text { Trevisol e Lima (2014); Mulik (2014); Hibarino (2015); Reis et } \\
\text { al. (2014b); Justina (2016) }\end{array}$ \\
\hline
\end{tabular}

Fonte: Elaborado pelas autoras.

\section{Resultados alcançados}

Os resultados discorrem sobre aspectos dos focos levantados anteriormente: 0 Pibid em si, o Pibid como contexto, a formação inicial, a formação continuada, e a formação inicial e continuada em conjunto.

De maneira geral, os resultados enaltecem o programa e suas contribuições para a educação pública e para a formação de professores. Como exemplo, o trabalho de Lopes et al. (2014), cujo o foco foi o Pibid em si, concluiu que o programa proporciona um melhor conhecimento das particularidades da escola pública e do trabalho do professor de inglês, o que eleva a qualidade da formação, mostrando que o Pibid cumpre com seu objetivo principal. Além disso, o trabalho de Reis et al. (2014b), que teve o mesmo enfoque, evidencia em suas análises preliminares que há produtiva receptividade de ações que promovam melhorias no ensino-aprendizagem do inglês em escolas públicas brasileiras.

Em relação ao Pibid como contexto, foi possível observar resultados que dizem respeito ao uso da tecnologia em sala de aula e ao aprendizado dos alunos da educação básica. As pesquisas que trataram de ferramentas digitais concluíram que o aprendizado com tecnologia e games é visto como motivador pelos alunos, a exemplo da pesquisa de El Kadri (2015). Apesar disso, ficou claro que muitos professores não têm a formação digital necessária e precisam reconhecer a necessidade de letramento digital. 
Tendo ainda o Pibid como contexto, Trevisol, Santos e Alves (2014) avaliaram o ensino da oralidade e concluíram que, dentro de um ano, houve um aumento na motivação e na capacidade comunicativa dos participantes, além de um aprimoramento na formação acadêmica dos licenciandos. O trabalho de Rozenfeld e Salomão (2014), por sua vez, constatou que as atividades desenvolvidas no Pibid e que foram descritas na pesquisa contribuíram para a formação reflexiva dos pibidianos no que diz respeito ao tratamento do tema cultura no ensino de línguas.

Os estudos sobre formação inicial mostram que o programa eleva a qualidade da formação e contribui para a reflexão e para o estabelecimento da identidade dos licenciandos, bem como para a negociação dessa identidade, isto é, as identidades não são estáticas e definitivas. Por exemplo, o trabalho de Rocha et al. (2014) conclui que a participação no Pibid tem sido uma conflituosa e instigante experiência de formação, fazendo com que a identidade e representação dos pibidianos sejam continuamente (des)construídas e mobilizadas, além de favorecer o desenvolvimento da autonomia e a construção de uma identidade agente e empoderada. Segundo esse estudo, o programa tem favorecido o processo de reflexão dos professores em formação sobre si mesmos e sobre o que é ser professor.

Ainda nas pesquisas sobre formação inicial, o Pibid evidenciou-se como um espaço no qual surgem novas ideias e rumos para o desenvolvimento dos futuros professores, como mostram Petreche e Silva (2018), que concluíram que o estudo das representações, dos posicionamentos ideológicos dos pibidianos e de como eles constroem sentidos em sua participação no programa possibilita avanços na produção de conhecimento sobre a formação de professores de inglês, além de evidenciar a relevância da atuação em projetos coletivos ao longo da graduação. Os resultados dos estudos também demonstraram que entre os significados produzidos pelos licenciandos estão as dificuldades, ansiedades e desejos dos participantes em sala de aula e que questões sobre "como ensinar" e "como fazer em sala de aula" ainda são desafios para o alunoprofessor.

Em sua maioria, os resultados a respeito da formação inicial caracterizam o Pibid como um contexto favorável para a aprendizagem docente. Neste espaço de formação inicial ocorrem diferentes movimentos, também de resistência e embate, na (re)construção identitária. Sobre isso, El Kadri (2018), ao analisar a trajetória de uma pibidiana, destaca ser a participação ativa dos professores em formação prática um ato 
que favorece o diálogo e contribui para que eles evoluam de uma identidade resistente e negativa para uma agente e empoderada, uma vez que se veem como agentes de mudança.

Ainda dentre os trabalhos que tratam da formação inicial, os resultados do estudo de Reichmann e Morais (2018, p. 17) evidenciaram o surgimento de novas vozes docentes no entrelaçamento entre as histórias de vida de licenciandos e alunos, pois, em meio aos conflitos do cotidiano de sala de aula, os licenciandos assumem uma postura que pode desenvolver a voz de "professor-autor".

Também ficou clara a relevância da articulação entre universidade e escola, uma vez que, por meio da inserção gradual dos licenciandos no ambiente escolar, foi possível notar o desenvolvimento de práticas de ensino e de materiais didáticos mais eficientes e de acordo com os documentos oficiais de ensino, conforme aponta Baladeli (2015).

A pesquisadora mencionada apontou ainda que a participação no programa contribui para a formação inicial e para a aprendizagem da profissão, pois esta proporciona o desenvolvimento de uma postura de professor pesquisador, além de favorecer a compreensão do papel do professor e da função social a ser exercida enquanto professor de língua inglesa.

Os resultados da pesquisa de Baladeli (2015), a exemplo, mostram que, se por um lado o Pibid tem contribuído para a formação da identidade profissional dos licenciandos e para a compreensão do papel social do professor de língua inglesa, o programa também tem mostrado a complexidade de se formar professores de inglês interessados em atuar no contexto do Ensino Básico público.

No que tange à formação continuada, os resultados reforçam a relevância do programa e das práticas colaborativas, a exemplo da pesquisa de Trevisol e Lima (2014), cujas conclusões destacaram que participar do Pibid é uma experiência enriquecedora de formação continuada, visto que permitiu à supervisora uma reflexão sobre a prática pedagógica, por meio dos encontros de estudo, das leituras teóricas, das trocas de experiências e das intervenções para o ensino da oralidade em inglês que aconteceram no projeto.

O olhar para os professores supervisores evidenciou o seu papel de coformador, assistente e aprendiz. Nesse sentido, outros estudos que abordaram a formação continuada constataram que os momentos de feedback são ressaltados como indispensáveis para a reflexão sobre a prática docente e para a negociação de sentidos, 
como ressaltou a pesquisa de Hibarino (2015), que buscou entender como as professoras supervisoras constroem seus papéis de coformadoras ao lidar com os conflitos.

A pesquisa de Reis et al. (2014a), que buscou analisar as expectativas de duas professoras supervisoras diante da inserção do projeto no cotidiano de sala de aula, evidenciou, em seus resultados preliminares, grande receptividade na escola pública para projetos como o Pibid, visto que eles promovem avanços no ensino-aprendizagem de língua inglesa.

Estudos que se atentaram para a formação inicial e continuada, como o de Silva (2015), indicaram a ressignificação e o fortalecimento da relação entre escola e universidade, o que resultou em práticas colaborativas e no enfraquecimento de hierarquias. Além disso, o programa caracterizou-se como uma experiência enriquecedora na qual destaca-se a importância da colaboração entre os participantes e da mediação, mesmo com a existência de tensões. Nesse sentido, o estudo de Mulik (2018) evidenciou que o uso de diários contribuiu para o compartilhamento de dificuldades nos momentos de troca entre os participantes, mostrando que a colaboração entre eles foi ferramenta chave na busca de soluções.

Conforme apontam Mateus e Fiori-Souza (2017), cuja pesquisa considerou tanto os coordenadores quanto os supervisores e pibidianos, o programa é um espaço no qual professores/as e estudantes podem experimentar conflitos, engajamento e transformação. Nesse sentido, de acordo com os resultados de Gaffuri (2018), a formação colaborativa demanda tempo e respeito, a fim de que haja de fato ressignificação de papéis sociais.

\section{Discussão dos resultados}

Com base nos resultados observados, teceremos considerações a respeito de pontos bastante explorados (que denominamos de avanços) e outros ainda lacunares em relação a investigações sobre o Pibid.

Alguns dos resultados mostraram como ocorreu a ressignificação de identidades, papéis e relações vistas através dos olhos dos pibidianos dentro do programa, como apontam: Araújo (2015), sobre ressignificação de crenças; Silva (2015), sobre a ressignificação da relação escola e universidade; e Gaffuri (2018), sobre papéis sociais. 
Também foram constatados resultados, em Mulik (2014) e Hibarino (2015), que observam o papel do supervisor como coformador no desenvolvimento dos pibidianos.

Ainda sobre os avanços, é possível perceber o Pibid como um lugar de experienciar práticas alternativas, uma vez que entre as pesquisas levantadas foi observada a utilização de novas metodologias, ou metodologias alternativas, como mostra El Kadri (2015), sobre a metodologia de game-based learning, Trevisol, Santos e Alves (2014), sobre perspectivas do ensino de oralidade em inglês, e Reis e Sabota (2015), sobre a utilização da ferramenta de vodcast em sala de aula.

Também observamos um relato sobre os conflitos dos pibidianos relacionados às dificuldades encontradas na profissão professor, como apontam Fiori-Souza (2014), Mateus e Fiori-Souza (2017), Hibarino (2015) e Mulik (2018).

Em relação à metodologia de pesquisa em si, os instrumentos vislumbrados neste mapeamento demonstram uma variedade de formas pelas quais os estudos foram desenvolvidos, revelando que existem diversas maneiras de conduzir trabalhos relacionados ao Pibid. Assim, pesquisas cujos temas são relacionados ao Pibid ainda podem prosperar, fazendo com que os resultados obtidos até agora e no futuro otimizem as possibilidades do programa.

Por conseguinte, com esses vários enfoques investigativos e metodológicos, podemos dizer que o Pibid, além de um espaço de formação docente, é também um contexto para se desenvolver pesquisas de modo a melhor compreender essa política pública de formação de professores e seus desdobramentos.

Considerando, então, os trabalhos levantados, pontuamos aqui alguns focos ainda pouco explorados que podem ser alvo de estudos futuros. Por exemplo, há oportunidades de pesquisa no que tange aos/às coordenadores/as do programa, visto que não observamos no mapeamento pesquisas que levantaram de modo exclusivo dados sobre a experiência de formação dos formadores. As supervisoras do programa e sua formação continuada também configuram um foco que poderia ser mais investigado futuramente, uma vez que apenas cinco dos trabalhos levantados abordavam o tema.

Ainda falando dos atores do programa, há oportunidades para pesquisas sobre os egressos do Pibid, investigando se estes estão exercendo cargos de professor depois que deixaram o programa ou a universidade, e, onde eles estão trabalhando enquanto graduados. Ademais, as investigações com foco na grade curricular dos cursos de Letras, 
olhando especialmente para os estágios e suas articulações com o Pibid poderiam também ter destaque.

\section{Considerações finais}

O presente artigo realizou um levantamento de estudos recentes, desenvolvidos entre os anos de 2014 a 2018, que tratam da formação de professores de língua inglesa no contexto do Pibid. Mapeamos os focos investigativos, a metodologia empregada e os participantes da pesquisa, além dos resultados alcançados.

De modo geral, foi evidenciado um foco de investigação mais predominante na formação docente inicial, com os alunos de graduação participantes do programa. As pesquisas qualitativas se sobressaem, ainda que nem todas tragam a natureza da investigação em seus resumos ou introduções, com o emprego de diferentes instrumentos para coleta/geração de dados.

Ao destacar alguns dos avanços e lacunas em relação a investigações sobre o Pibid, é esperado que o presente artigo contribua com o estado da arte do campo de formação de professores de línguas, em especial ao trazer nosso olhar para uma política pública de formação que tem impactado a aprendizagem de todos os envolvidos.

\section{Referências}

ALENCAR, Edvonete Souza; ALMOULOUD, Saddo Ag. A metodologia de pesquisa, a metassíntese qualitativa. Revista Reflexão e Ação, Santa Cruz do Sul, v. 25, n. 3, p. 204-220, set./dez. 2017. Disponível em: https://online.unisc.br/seer/index.php/reflex/article/\%20view/9731. Acesso em: 8 nov. 2020.

ARAUJO, Paula Serralha. Crenças e experiências de professores no Pibid de língua inglesa: interação e ressignificação. 2015. 112 f. Dissertação (Mestrado em Estudos Lingüísticos) - Universidade Federal de Uberlândia, Uberlândia, 2015.

BALADELI, Ana Paula D. Identity narratives of English teachers: the legacys of Pibid. 2015.238 f. Tese (Doutorado em Linguagem e Sociedade) - Universidade Estadual do Oeste do Paraná, Cascavel, 2015.

BALADELI, Ana Paula D.; VON BORSTEL, Clarice Nadir; FERREIRA, Aparecida de Jesus. Identidades docentes e diferença no discurso de professores de Língua Inglesa em formação inicial. Revista Portuguesa de Educação, Braga, v. 29, n. 1, p. 207-227, jun. 2016. Disponível em: 
http://www.scielo.mec.pt/scielo.php?script=sci_arttext\&pid=S087191872016000100010\&lng=pt\&nrm=iso. Acesso em: 6 jul. 2020.

BALADELI, Ana Paula Domingos. A tessitura das identidades profissionais de professores no contexto do PIBID - inglês. In: EL KADRI, Michele Salles; CALVO, Luciana Cabrini Simões; CHIMENTÃO, Lilian Kemmer; MULIK, Katia Bruginski (org.). $A$ formação de professores de inglês no contexto do PIBID: relatos de pesquisas acadêmicas. Campinas: Pontes Editores, 2018. p. 163-195.

CAPES. Coordenação de Aperfeiçoamento de Pessoal de Nível Superior. PIBID Programa Institucional de Bolsa de Iniciação à Docência. Edital no 7. 2018. Disponível em: https://www.gov.br/capes/pt-br/centrais-de-conteudo/120318-edital-0631954edital-capes-07-2018-pibid-retificado-pdf. Acesso em: 18 mar. 2021.

CHIMENTÃO, Lilian Kemmer. Desenvolvimento profissional de professores de inglês: a percepção de si e do outro. In: EL KADRI, Michele Salles; CALVO, Luciana Cabrini Simões; CHIMENTÃO, Lilian Kemmer; MULIK, Katia Bruginski (org.). A formação de professores de inglês no contexto do PIBID: relatos de pesquisas acadêmicas.

Campinas: Pontes Editores, 2018. p. 133-162.

CHIMENTÃO, Lilian Kemmer. Identidades profissionais docentes e relações sociais no Pibid. In: CONGRESSO LATINO-AMERICANO DE FORMAÇÃO DE PROFESSORES DE LÍNGUAS - CLAFPL, 5., 2014. Goiânia. Anais [...]. Goiânia: Universidade Federal de Goiás, 2014. p. 190-200. Disponível em:

https://files.cercomp.ufg.br/weby/up/475/o/vclafpl_anais.pdf. Acesso em: 6 jul. 2020.

DENARDI, Didiê Ceni. Subprojeto PIBID: extensão universitária para a formação de professores de língua inglesa. Extramuros, Petrolina, v. 2, n. 2, p. 86-101, jul./dez. 2014. Disponível em:

http://www.periodicos2.univasf.edu.br/index.php/extramuros/article/view/457/229. Acesso em: 6 jul. 2020.

EL KADRI, Michele Salles. Transformando a atividade de formação de professores/as de inglês: o uso da plataforma Fazgame para o ensino e formação de professores no contexto do Pibid. Revista Edapeci, São Cristovão, v. 15, n. 1, p. 102-116, jan./abril 2015. Disponível em: https://seer.ufs.br/index.php/edapeci/article/view/3707. Acesso em: 6 jul. 2020.

EL KADRI, Michele Salles. Understanding teacher identities in a local interpretation of PIBID: implementing \{coteaching / cogenerative dialogue\}. In: EL KADRI, Michele Salles; CALVO, Luciana Cabrini Simões; CHIMENTÃO, Lilian Kemmer; MULIK, Katia Bruginski (org.). A formação de professores de inglês no contexto do PIBID: relatos de pesquisas acadêmicas. Campinas: Pontes Editores, 2018. p. 109-131.

EL KADRI, Michele Salles; CALVO, Luciana Cabrini Simões; CHIMENTÃO, Lilian Kemmer; MULIK, Katia Bruginski (org.). A formação de professores de inglês no contexto do PIBID: relatos de pesquisas acadêmicas. Campinas: Pontes Editores, 2018.

FIORI-SOUZA, Adriana Grade. Resistência e mudança na práxis colaborativa do Pibid. In: CONGRESSO LATINO-AMERICANO DE FORMAÇÃ̃O DE PROFESSORES DE LÍNGUAS - 
CLAFPL, 5., 2014. Goiânia. Anais [...]. Goiânia: Universidade Federal de Goiás, 2014. p. 417-428. Disponível em: https://files.cercomp.ufg.br/weby/up/475/o/vclafpl_anais.pdf. Acesso em: 6 jul. 2020.

GAFFURI, P. PIBID - Inglês/UEL: ressignificando o espaço da formação inicial e contínua de professores. In: EL KADRI, Michele Salles; CALVO, Luciana Cabrini Simões; CHIMENTÃO, Lilian Kemmer; MULIK, Katia Bruginski (org.). A formação de professores de inglês no contexto do PIBID: relatos de pesquisas acadêmicas. Campinas: Pontes Editores, 2018. p. 19-46.

GIMENEZ, Telma. Formação de professores de línguas no Brasil: avanços e desafios. In: SANTOS, Leandra Ines Seganfredo; SILVA, Kleber Aparecido (org.). Linguagem, ciência e ensino: desafios regionais e globais. Campinas: Pontes Editores, 2013. p. 41-54.

HIBARINO, Denise Akemi. Co-formação, conflitos e negociações no PIBID-INGLÊS UFPR. Revista X, Curitiba, v. 1, p. 16-31, jun. 2015. Disponível em: https://revistas.ufpr.br/revistax/article/view/37557/25493. Acesso em: 6 jul. 2020.

JORDÃO, C. M. Prefácio - mais um. In: EL KADRI, Michele Salles; CALVO, Luciana Cabrini Simões; CHIMENTÃO, Lilian Kemmer; MULIK, Katia Bruginski. (org.). $A$ formação de professores de inglês no contexto do PIBID: relatos de pesquisas acadêmicas. Campinas: Pontes Editores, 2018. p. 7-11.

JUSTINA, O. D. O papel da supervisora de área na coformação por meio do Programa Institucional de Bolsa de Iniciação à Docência (PIBID): língua inglesa. 2016.176 f. Tese (Doutorado em Estudos Linguísticos) - Universidade Estadual Paulista Júlio de Mesquita Filho, São José do Rio Preto, 2016.

KAUST, Ana Maria; PAIZAN, Delfina Cristina. 0 impacto do Pibid na formação das competências dos futuros professores de língua inglesa. In: RIBEIRO, Dulcyene Maria; CONTERNO, Solange de Fátima Reis; MARTELLI, Andréa Cristina; STRIEDER, Dulce Maria; JUSTINA, Lourdes Aparecida Della (org.) Trajetórias de iniciação à docência no Pibid. Toledo: Indicto Editora, 2017. p. 129-139. Disponível em: http://indicto.com.br/site/uploads/rar/722899fd90119a120b133076ce3c912b.pdf. Acesso em: 7 jul. 2020.

LANFERDINI, Priscila Azevedo Fonseca; CRISTOVÃO, Vera Lucia Lopes. Pibidianos confrontados com a própria prática: reflexões emergentes em uma sessão de autoconfrontação simples. In: EL KADRI, Michele Salles; CALVO, Luciana Cabrini Simões; CHIMENTÃO, Lilian Kemmer; MULIK, Katia Bruginski (org.). A formação de professores de inglês no contexto do PIBID: relatos de pesquisas acadêmicas. Campinas: Pontes Editores, 2018. p. 75-107.

LOPES, Cristiane Rosa; SOUZA, Maria Izeldes Alves; CRUZ, Ana Clécia Dias; PEREIRA, Brenda Barbosa; QUEIROS, George Breno dos Santos; SILVA, Jullyane Prado Amaral; CARMO, Milton Cássio Andrade; JESUS, Vanessa Pereira. Proposta do Pibid LetrasInglês da UEG de Campos Belos para o aprimoramento da formação de professores/as e da qualidade do ensino de língua inglesa. In: CONGRESSO DE ENSINO, PESQUISA E EXTENSÃO DA UEG, 1., 2014, Pirenópolis. Anais [...] Pirenópolis: Universidade Estadual 
de Goiás, 2014. Disponível em:

https://www.anais.ueg.br/index.php/cepe/article/view/9693. Acesso em: 6 jul. 2020.

MAIA, Angélica Araújo de Melo. Leituras do mundo da escola de professores de inglês em formação dentro de um projeto Pibid: desvendando complexidades e desenhando possibilidades de ação. In: CONGRESSO LATINO-AMERICANO DE FORMAÇÃO DE PROFESSORES DE LÍNGUAS - CLAFPL, 5., 2014. Goiânia. Anais [...]. Goiânia: Universidade Federal de Goiás, 2014. p. 235-244. Disponível em: https://files.cercomp.ufg.br/weby/up/475/o/vclafpl_anais.pdf. Acesso em: 6 jul. 2020.

MATEUS, Elaine; FIORI-SOUZA, Adriana Grade. Deliberação e formação críticocolaborativa de professores/as. In: MATEUS, Elaine; TONELLI, Juliana Reichert Assunção (org.). Diálogos (im)pertinentes entre formação de professores $e$ aprendizagem de línguas. São Paulo: Blucher, 2017. p. 37-56. Disponível em: https://openaccess.blucher.com.br/article-details/02-20650. Acesso em: 6 jul. 2020.

MOTTA, Ana Luiza Artiaga R.; SILVA, Valdir. Os efeitos do Pibid na formação de alunos da área da linguagem: uma reflexão amparada nas práticas de Estágio Supervisionado. Revista Polyphonía, Goiânia, v. 25, n. 1, p. 145-159, 2014.

MULIK, Katia Bruginski. Diário de bordo on-line como ferramentas de reflexão: um estudo com os participantes do PIBID - Inglês da UFPR. In: EL KADRI, Michele Salles; CALVO, Luciana Cabrini Simões; CHIMENTÃO, Lilian Kemmer; MULIK, Katia Bruginski (org.). A formação de professores de inglês no contexto do PIBID: relatos de pesquisas acadêmicas. Campinas: Pontes Editores, 2018. p. 47-74.

MULIK, Katia Bruginski. O Programa Institucional de Bolsas de Iniciação à Docência (PIBID) como espaço de formação continuada de professores de língua inglesa. 2014. 187 f. Dissertação (Mestrado em Letras) - Universidade Federal do Paraná, Curitiba, 2014.

NERES, Fernanda Passos da Trindade Jorge. O PIBID como espaço para 0 desenvolvimento da autonomia de professores de língua inglesa em formação inicial. 2014. 112 f. Dissertação (Mestrado em Linguística Aplicada) - Universidade Federal do Rio de Janeiro, Rio de Janeiro, 2014.

PETRECHE, Célia Regina Capellini; SILVA, Emanuele Cricia Oliveira. Representações de pibidianos de língua inglesa e desenvolvimento docente. Revista Claraboia, Jacarezinho, v. 10, p. 183-206, jul./dez. 2018. Disponível em:

http://seer.uenp.edu.br/index.php/claraboia/article/view/1400/pdf. Acesso em: 7 jul. 2020.

REICHMANN, Carla Lynn; MORAIS, Daniel Sousa. Um estudo sobre dizeres de licenciandos cotistas no Pibid: 'três lanches, professora?'. The Especialist, São Paulo, v. 39, n. 1, p. 1-19, jul. 2018. Disponível em: https://revistas.pucsp.br/esp/article/view/37168. Acesso em: 6 jul. 2020.

REIS, Mary Soares Almeida; SABOTA, Barbra. O uso da ferramenta Vodcast e o ensino de língua inglesa no contexto escolar: uma contribuição dos professores em formação no Pibid. In: SEMINÁRIO DE PESQUISA, PÓS-GRADUAÇÃO, ENSINO E EXTENSÃO DO 
CCSEH, 1., 2015, Anápolis. Anais [...]. Anápolis: Universidade Estadual de Goiás, 2015.p. 1-5. Disponível em:

https://www.anais.ueg.br/index.php/sepe/article/view/6528. Acesso em: 7 jul. 2020.

REIS, Valdeni da Silva; PAULA, Guilherme Fonseca; GÓES, Lara do Nascimento; LIMA, Sueli Alves Oliveira. Não só de verbo to be sobre(vive) o ensino de língua inglesa: análise das expectativas e anseios de duas professoras e seus alunos ao receber o Pibid em sua sala de aula. In: CONGRESSO LATINO-AMERICANO DE FORMAÇÃO DE PROFESSORES DE LÍNGUAS - CLAFPL, 5., 2014. Goiânia. Anais [...]. Goiânia: Universidade Federal de Goiás, 2014a. p. 282 - 289. Disponível em: https://files.cercomp.ufg.br/weby/up/475/o/vclafpl_anais.pdf. Acesso em: 6 jul. 2020.

REIS, Valdeni da Silva; ROCHA, Ana Maria Santos; ÁVILA, Isabel Cristina Otone; ARAUUO, Julien Valéry Melo; FERNANDES, Renan Felipe dos Santos; PAULA, Guilherme Fonseca; PEREIRA, Iza Carla; GOÉS, Lara do Nascimento. Não só de verbo to be sobre(vive) o ensino da língua inglesa: a implementação do Pibid em duas escolas do vale do Jequitinhonha. In: CONGRESSO LATINO-AMERICANO DE FORMAÇÃO DE PROFESSORES DE LÍNGUAS - CLAFPL, 5., 2014. Goiânia. Anais [...]. Goiânia: Universidade Federal de Goiás, 2014b. p. 272 - 281. Disponível em: https://files.cercomp.ufg.br/weby/up/475/o/vclafpl_anais.pdf. Acesso em: 6 jul. 2020.

ROCHA, Ana Maria Santos; PEREIRA, Iza Carla; REIS, Marina Lopes Rocha; FERNANDES, Renan Felipe dos Santos; DIAS, Suely Aparecida; REIS, VALDENI DA Silva. A formação inicial do graduando em Letras a partir de sua atuação no Pibid: deslocamentos identitários, representações e o outro lado da moeda. In: CONGRESSO LATINO-AMERICANO DE FORMAÇÃO DE PROFESSORES DE LÍNGUAS - CLAFPL, 5., 2014. Goiânia. Anais [...]. Goiânia: Universidade Federal de Goiás, 2014. p. 9-17. Disponível em https://files.cercomp.ufg.br/weby/up/475/o/vclafpl_anais.pdf. Acesso em: 6 jul. 2020.

ROCHA, Nildicéia Aparecida. Projeto pontes PIBID letras: ações e reflexões sobre a formação de professores de línguas estrangeiras. In: CONGRESSO NACIONAL DE FORMAÇÃO DE PROFESSORES, 2.; CONGRESSO ESTADUAL PAULISTA SOBRE FORMAÇÃO DE EDUCADORES, 12., 2011, Águas de Lindóia. Anais [...]. São Paulo: UNESP; PROGRAD, 2014. p. 1074-1084 Disponível em: http://hdl.handle.net/11449/141719. Acesso em: 6 jul. 2020.

ROMERO, Tania Regina S. Pibid: prós, contras e (e)feitos. In: MATEUS, Elaine; TONELLI, Juliana Reichert Assunção (org.). Diálogos (im)pertinentes entre formação de professores e aprendizagem de línguas. São Paulo: Blucher, 2017. p. 57-76. Disponível em: https://openaccess.blucher.com.br/article-details/03-20651. Acesso em: 6 jul. 2020.

RORRATO, Déborah Caroline Cardoso Pereira. O ensino colaborativo e a prática do PIBID. Intercâmbio: revista do programa de estudos pós-graduados em linguística aplicada e estudos da linguagem, São Paulo, v. 29, p. 169-185, out. 2014. Disponível em: https://revistas.pucsp.br/intercambio/article/view/20965. Acesso em: 6 jul. 2020.

ROZENFELD, Cibele Cecílio de Faria; SALOMÃO, Ana Cristina Biondo. O trabalho de licenciandos em alemão e inglês no Pibid: a construção da prática docente a partir das 
crenças de alunos do ensino médio sobre língua e cultura estrangeira. Revista Horizontes da Linguística Aplicada, Brasília, v. 13, n. 1, p. 159-179, 2014. Disponível em: http://hdl.handle.net/11449/125207. Acesso em: 6 jul. 2020.

SILVA, Themis Rondão da Costa. Um olhar situado sobre a ecologia de saberes no PIBID: multiletramento e formação de professores de língua inglesa. 2015. $120 \mathrm{f}$. Dissertação (Mestrado em Letras) - Universidade Estadual do Mato Grosso do Sul, Campo Grande, 2015.

SILVESTRE, Viviane Pires Viana. Construção colaborativa de um plano de aula de inglês em um contexto do Pibid: um olhar a partir da perspectiva sociocultural. Revista Atos de Pesquisa em Educação, Blumenau, v. 9, n. 3, p. 641-661, set./dez. 2014. Disponível em: https://proxy.furb.br/ojs/index.php/atosdepesquisa/article/view/4258/2825. Acesso em: 7 jul. 2020.

TREVISOL, Juliane Regina; LIMA, Regivania Almeida. Pibid inglês: uma experiência significativa de formação continuada. Revista Eletrônica Falas Breves, Breves, v. 1, n. 1. fev. 2014. Disponível em: http://www.falasbreves.ufpa.br/index.php/revista-falasbreves/issue/view/1. Acesso em: 6 jul. 2020.

TREVISOL, Juliane Regina; SANTOS, Gisele Moreira; ALVES, Jailda Passos. Oportunizando perspectivas de ensino da oralidade em inglês: uma experiência do Pibid para a formação docente. Revista Eletrônica Falas Breves, Breves, v. 1, n. 1, fev. 2014. Disponível em: http://www.falasbreves.ufpa.br/index.php/revista-falasbreves/article/view/15/21. Acesso em: 6 jul. 2020.

ZANELLA, Daniela Aparecida Vendramini; CARNEIRO, Maria Angélica Lauretti. A produção de significados na atividade de formação do Pibid/Uniso de língua inglesa. Revista Polyphonía, Goiânia, v. 25, n.1, p. 113-130, 2015.

Submetido em: 01 set. 2020. Aceito em: 24 nov. 2020. 